Article

\title{
Genetics of Height and Branching in Faba Bean (Vicia faba)
}

\author{
Jessa Hughes, Hamid Khazaei * (D) and Albert Vandenberg \\ Department of Plant Sciences, University of Saskatchewan, Saskatoon, SK S7N 5A8, Canada; \\ jessa.hughes@usask.ca (J.H.); bert.vandenberg@usask.ca (A.V.) \\ * Correspondence: hamid.khazaei@usask.ca; Tel.: +1-306-966-8786
}

Received: 1 July 2020; Accepted: 10 August 2020; Published: 13 August 2020

check for updates

\begin{abstract}
A better understanding of the genetics of plant architecture, including height and branching, could improve faba bean breeding for varieties with better fit into specific cropping systems. This study aimed to determine the inheritance and genetic interactions of the sources of the dwarf gene (dwf1) and semi-dwarf gene (dwarf1), and to investigate the genetics of branching in the faba bean. We chose inbred lines IG 12658 (dwarf, carrying dwf1) and Rinrei (semi-dwarf, carrying dwarf1) along with Aurora/2 and IG 114476 as sources of non-dwarf faba bean genotypes and crossed them (Aurora/2 $\times$ IG 12658, IG 114476 × IG 12658, Rinrei × IG 12658, IG $114476 \times$ Rinrei, and Rinrei × Aurora/2). IG 114476 was also used as a genetic source of a highly branching phenotype and crossed with IG 12658, Rinrei, and Aurora/2 to study the genetics of branching. Parental lines, $F_{1} s$, and $F_{2}$ populations were evaluated under growth chamber and field conditions in 2018. The segregating $\mathrm{F}_{2}$ populations were tested for 3:1 single recessive gene inheritance using Chi-square tests. Both dwarfing/semi-dwarfing genes fit 3:1 recessive, and 15:1 for double recessive. Rinrei was not a true $\mathrm{dwarf}$, and the gene creating the dwarf appearance reduced the initial growth rate, but this corrected over time. Multiple $\mathrm{F}_{2}$ populations were also tested for a 3:1 single dominant gene hypothesis for highly branched phenotypes. These populations showed a bell-shaped phenotypic distribution for branch number, with no discernable classes, and revealed that branching was likely quantitatively controlled. In conclusion, dwarfism and branching in faba bean were controlled qualitatively and quantitatively, respectively.
\end{abstract}

Keywords: dwarfism; branching; inheritance; broad bean; Mendelain segregation

\section{Introduction}

Dwarf plants are commonly used in agricultural systems as a method of improving agronomic traits. In wheat (Triticum aestivum), for example, dwarfism was used to reduce lodging and improve yields during the Green Revolution. A key driver of the Green Revolution was the introduction of the Rht semi-dwarfing genes [1]. Dwarf mutations also exist in legume species (reviewed by Huyghe [2]). To date, six dwarfing sources have been reported in faba bean. The first published record was $d w 1$ found in cultivar Compacta [3]. Nearly a decade later, $d w 2$ gene, found in a spontaneous mutation, was reported by Sjödin [4]. The $d w 3$ gene, also a spontaneous mutation, was found in line HG 115C at INRA (Institut National de la Recherche Agronomique), France. The $d w 4$ [5] and $d w 5$ [6] dwarfing genes were created through mutagenesis using $X$-ray and EMS (ethyl methane sulfonate), respectively. Genotype Rinrei was introduced in 2004 as a dwarf/semi-dwarf mutant that was created by $\gamma$-ray irradiation and was designated dwarf1 $[7,8]$. The genetic interactions among these reported sources remain unresolved.

Two mechanisms of dwarfism identified to date in faba bean are both the result of incomplete hormone biosynthesis, either gibberellic acid (GA) or brassinosteroid (BR). The mechanism for the $d w 1$ gene was identified as a GA deficiency [9]. Professor Donal O'Sullivan recently identified another GA 
deficiency gene (personal communication) in a dwarf Ethiopian faba bean landrace IG 12658 (dwf1, Webb et al. [10]). The GA promotes cell elongation, germination, and flowering [11]. Gibberellin insensitivity is caused by mutations in the genes that encode gibberellin-signaling proteins [12]. This results in an abnormal response to gibberellins and reduced plant growth. The dwarf1 gene was shown to be a BR deficient mutant [7]. The BRs are steroidal growth-promoting plant hormones [13] that also serve as stress response hormones. Several BR-dwarf mutants have been isolated from pea (Pisum sativum L.) [14] and other plant species [15,16].

Branching is also an important agronomic trait. In large-scale agricultural systems, branching can improve crop competitiveness by shading out weeds between seed rows [17,18]. This also improves light absorption by increasing the canopy leaf area [19]. The degree of branching varies genotypically in faba bean germplasm, and its expression is influenced by growing conditions and sowing dates [20]. In a collection of 5000 faba bean accessions, the number of branches per plant ranged from 1.1 to 11.4 [21]. Understanding these key architectural traits will help breeders to diversify the faba bean cultivation in organic production systems. Basic genetic studies of plant height, branching, and their interaction in faba bean are generally lacking. The objectives of these investigations were (1) to determine the inheritance and genetic interactions of the two independent sources of dwarf-inducing deficiencies ( $d w f f$ and dwarf1) in faba bean, and (2) to determine the genetics of the branching phenotype in this species.

\section{Materials and Methods}

\subsection{Plant Material}

The plant materials consisted of four faba bean inbred lines differing in plant height and architecture. IG 12658 (Accession DOI\# 10.18730/60V47) is a dwarf accession from Ethiopia [10]. Rinrei is a semi-dwarf mutant variety created by $\gamma$-ray irradiation from the variety Niigata-zairai in Japan. Rinrei is defective in its ability to reduce sterol C-24, resulting in a brassinosteroid deficiency, and therefore, shortened stature. Rinrei is phenotypically characterized as having short internode length and short petiole length [7,8]. IG 114476 (Accession DOI\# 10.18730/8VJQF) is a Paucijuga-type faba bean with small seeds, short stature, and highly branched main stem growth habit from Bangladesh [22]. Aurora/2 is a relatively tall genotype with high productivity from Sweden [23].

\subsection{Hybridization}

The crosses Aurora/2 $\times$ IG 12658 (tall $\times$ dwarf), IG $114476 \times$ IG 12658 (short-stature $\times$ dwarf), Rinrei $\times$ IG 12658 (semi-dwarf $\times$ dwarf), IG $114476 \times$ Rinrei (short-stature $\times$ semi-dwarf), and Rinrei $\times$ Aurora/2 (semi-dwarf $\times$ tall) were prepared by manual pollinations in an insect-proof growth chamber in the Controlled Environment Facility of the College of Agriculture and Bioresources, University of Saskatchewan, Canada. IG 114476 was also crossed with other three parental lines (IG 12658, Rinrei, and Aurora/2) to study branching patterns. Parental lines and $\mathrm{F}_{1}$ seeds were grown in $4 \mathrm{~L}$ pots and were inoculated with Rhizobium leguminosarum bv. viciae to maximize their seed productivity during the crossing period and $\mathrm{F}_{2}$ seed production.

\subsection{Growing Conditions}

\subsubsection{Growth Chamber}

The parental lines, $\mathrm{F}_{1}$, and $\mathrm{F}_{2}$ seeds were grown in crates $(30 \times 30 \times 27 \mathrm{~cm})$ lined with polypropylene grain bags filled with Sun-Gro potting mix No. 3 (Sun-Gro Horticulture, Agawam, MA, USA) and placed in a growth chamber. Plants were seeded at a density of four plants per container on 5 October 2018 and grown for $96 \mathrm{~d}$ before being harvested and measured. The photoperiod of the chamber was set to $14 / 10 \mathrm{~h}$ (light/dark). The photosynthetic photon flux density was $\sim 300 \mu \mathrm{mol} \mathrm{m}{ }^{-2} \mathrm{~s}^{-1}$ at the plant canopy level. The temperature was adjusted to $21^{\circ} \mathrm{C}$ light $/ 15^{\circ} \mathrm{C}$ dark. Plants were watered as necessary and fertilized with a blend of 15-30-15 (N-P-K) biweekly after the $10^{\text {th }}$ node stage. The sample sizes for 
phenotypic analysis for each cross were seven plants each for parental lines and $\mathrm{F}_{1} \mathrm{~s}$. The $\mathrm{F}_{2}$ population size ranged from 14 to 84 individual plants. The crates were randomized within each cross.

\subsubsection{Field}

To accurately test height and branching, plants required equidistant spacing. To ensure natural light conditions and equal spacing requirements were met, parental lines, $\mathrm{F}_{1} \mathrm{~s}$, and $\mathrm{F}_{2}$ populations segregating for dwarfism and branching traits were seeded into $12 \mathrm{~cm}$ deep Rootrainer ${ }^{\mathrm{TM}}$ (Gardener's Supply Company, Burlington, VT, USA) transplant containers on 16 April 2018. From 9-16 May, the transplants were hardened off outside during the day, and were covered with a tarp at night to avoid frost risk. Black plastic mulch was laid with a Plastic Mulch Layer Model 560 (Rain Flo Irrigation, East Earl, USA). On 16 May 2018, the young plants were transplanted into black plastic mulch with $25 \mathrm{~cm}$ spacing between plants in the field with a Vegetable Transplanter Model 1400 (Rain Flo Irrigation) on 16 May 2018. The transplants were fertilized with 20-20-20 (N-P-K) and then watered for $15 \mathrm{~h}$ with an underlain drip tape to reduce transplant shock. In-season watering and fertilizer were applied biweekly as needed. The transplants grew for a total of $121 \mathrm{~d}$ before being pulled from the ground for measurement of plant morphological characteristics. The sample sizes in each cross were seven replicates for each parental line and $\mathrm{F}_{1} \mathrm{~s}$. The $\mathrm{F}_{2}$ population size varied from 93 to 314 individual plants.

\subsection{Phenotyping}

Four measurements were recorded for each plant in both the field and growth chamber experiments-plant height, number of branches, number of nodes, and node length. All plants were pulled from the soil and laid on a flat surface before measuring. The main stem height was recorded for each plant by measuring from base to apex. The number of branches was determined by counting all branches originating from main stem-secondary growth was excluded. The number of nodes on the main stem was recorded, beginning from the basal node to the stem apex, and mean internode node length was then calculated by dividing the stem height by the number of nodes. Aside from physical measurements, visual measurements were also recorded to classify the dwarf types into visually distinct categories on the basis of leaf color, leaf shape, and canopy structure. Pleiotropy in this study was observed with the dwarfing gene from Rinrei. It conveys multiple phenotypic effects on plants, including dark green foliage, short stature, short petioles, and thick stems. The pleiotropic relationship with the dwarf1 gene was used to classify the expression of the dwarf1 gene in the segregating populations. This is consistent with the conclusions of Fukuta et al. [7].

\subsection{Statistical Analysis}

All measurements were tested for deviations from normality using the Shapiro-Wilk test. The statistical goodness of fit of the observed offspring segregation ratios to their expected counterparts for dwarfing characteristics was determined by the standard Chi-squared $\left(\chi^{2}\right)$ test. Parameters were set based on measurements of the parental lines of the segregating populations and visible groupings on normal distribution histograms. These categories were then used to partition data into the qualitative categories appropriate for testing single gene hypotheses. The $\chi^{2}$ test was not performed for the branching data because no discrete categories were discernible, indicating that this is a quantitatively controlled trait. Standard errors of means (S.E.M.) were calculated. The R (R Development Core Team, [24]) was used for all the data analysis.

\section{Results}

The means, standard deviation, and range of plant height and internode length of parental lines, and their respective $F_{2}$ populations are shown in Table 1 . Aurora/2 was taller and had the longest internodes compared to the other three parental lines. IG 12658 had the shortest internodes (133, 60, and 31\% lower than Aurora/2, Rinrei and IG 114476, respectively). In general, the growth chamber-grown plants were taller than those grown under field conditions. IG 114476 was the shortest 
under the field conditions but not characterized as a dwarf due to larger internodes compared to IG 12658. All plants in the field experiments were shorter compared to the plants grown in the growth chamber, due to lessfavorable growing conditions in the field. IG114476 was the shortest, indicating it was most impacted by the field conditions.

Table 1. The mean \pm standard deviation (SD) and range for plant height and average internode length under the field and growth chamber conditions of parent lines and $\mathrm{F}_{2}$ faba bean crosses.

\begin{tabular}{cccccc}
\hline Parental Line/F 2 Cross & & \multicolumn{2}{c}{ Height (cm) } & \multicolumn{2}{c}{ Internode Length (cm) } \\
\hline & & Mean \pm SD & Range & Mean \pm SD & Range \\
\hline Aurora/2 & Field & $81.00 \pm 1.19$ & $71-96$ & $2.79 \pm 0.55$ & $2.29-3.69$ \\
IG 114476 & Growth chamber & $135.00 \pm 16.06$ & $112-147$ & $3.39 \pm 0.30$ & $3.06-3.73$ \\
& Field & $26.57 \pm 2.51$ & $23-30$ & $1.52 \pm 0.30$ & $0.91-1.86$ \\
IG 12658 & Growth chamber & $33.17 \pm 8.08$ & $23-45$ & $1.75 \pm 0.11$ & $1.53-1.86$ \\
& Field & $30.57 \pm 2.37$ & $27-34$ & $1.02 \pm 0.09$ & $0.94-1.15$ \\
Rinrei & Growth chamber & $19.71 \pm 0.95$ & $19-21$ & $0.62 \pm 0.07$ & $0.51-0.72$ \\
& Field & $41.00 \pm 6.08$ & $37-48$ & $1.62 \pm 0.13$ & $1.48-1.73$ \\
Aurora/2 $\times$ IG 12658 & Growth chamber & $46.75 \pm 5.50$ & $39-53$ & $1.40 \pm 0.13$ & $1.28-1.68$ \\
& Field & $56.14 \pm 15.54$ & $20-99$ & $2.20 \pm 0.59$ & $0.97-4.30$ \\
IG 114476 $\times$ IG 12658 & Growth chamber & $85.55 \pm 30.67$ & $31-146$ & $2.39 \pm 0.81$ & $0.84-3.76$ \\
& Field & $30.07 \pm 10.91$ & $9-64$ & $1.33 \pm 0.44$ & $0.56-2.56$ \\
Rinrei $\times$ IG 12658 & Growth chamber & $45.72 \pm 18.20$ & $12-94$ & $1.86 \pm 0.68$ & $0.58-3.03$ \\
IG 114476 $\times$ Rinrei & Field & $48.60 \pm 17.30$ & $11-90$ & $1.77 \pm 0.61$ & $0.44-3.29$ \\
& Growth chamber & $51.67 \pm 24.33$ & $14-105$ & $1.72 \pm 0.77$ & $0.45-3.75$ \\
Rinrei $\times$ Aurora/2 & Field & $35.99 \pm 8.35$ & $17-70$ & $1.75 \pm 0.31$ & $0.90-3.11$ \\
S.E.M. ${ }^{1}$ & Growth chamber & $33.87 \pm 7.83$ & $20-52$ & $1.60 \pm 0.29$ & $1.14-2.69$ \\
& Field & $72.60 \pm 20.33$ & $29-117$ & $2.50 \pm 0.53$ & $1.19-4.00$
\end{tabular}

${ }^{1}$ S.E.M., Standard errors of means.

Counts for normal and dwarf/semi-dwarf plants for each cross are shown in Table 2. Multiple crosses and $\mathrm{F}_{2}$ populations were examined to determine the inheritance of the two dwarfing genes from IG 12658 and the semi-dwarf from Rinrei. $F_{1}$ plants from the 'normal $\times$ dwarf' and 'normal $\times$ semi-dwarf' crosses produced normal height plants. The $\mathrm{F}_{2}$ results suggested a monogenic Mendelian inheritance (3 normal: 1 dwarf/semi-dwarf), with normal height dominant to dwarf phenotype under both controlled and field growing conditions. These results were in agreement with a bimodal distribution on the histogram (Figure 1A-R).

Table 2. Observed offspring segregation ratios, value of $\chi^{2}$ test, and the corresponding $p$-value for normal-height and (dwf1 and dwarf1 genes) phenotypes for $\mathrm{F}_{1}$ and $\mathrm{F}_{2}$ generations of faba bean crosses.

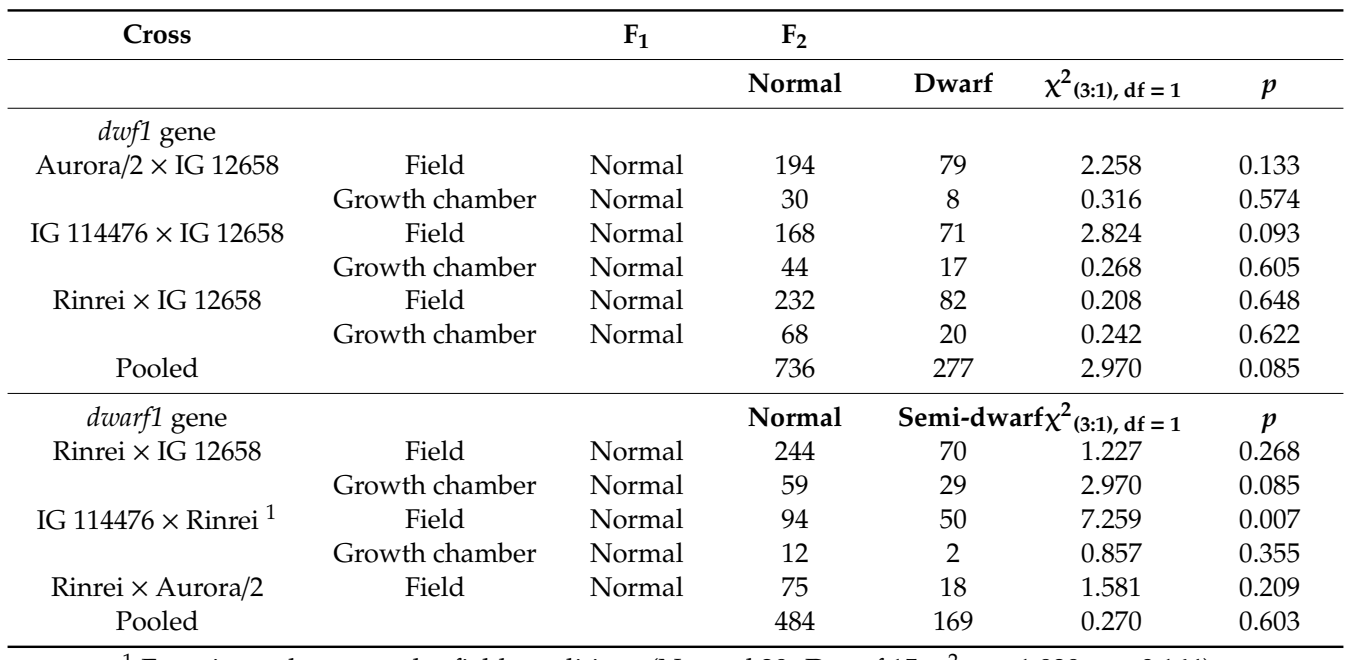

${ }^{1} \mathrm{~F}_{2}$ reciprocal cross under field conditions (Normal 29: Dwarf $15, \chi^{2}(3: 1): 1.939, p=0.164$ ). 

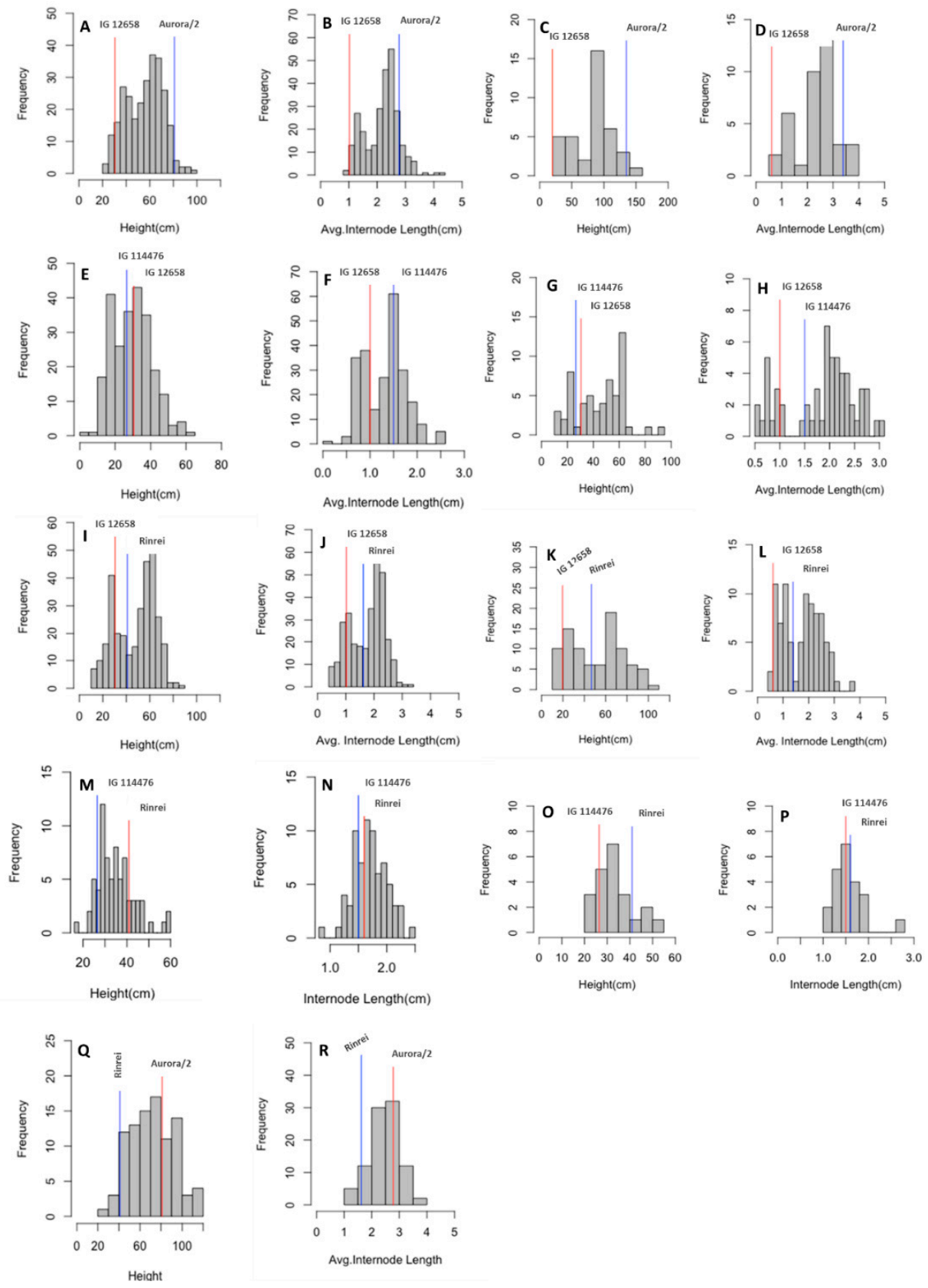

Figure 1. Frequency distributions of the height and average internode of the main stem for studied $\mathrm{F}_{2}$ populations. (A) Aurora/2 $\times$ IG 12658 height, field $(\mathrm{n}=273, P(\mathrm{~W})=0.001)$; (B) Aurora/2 $\times$ IG 12658 average internode, field $(\mathrm{n}=273, P(\mathrm{~W})=0.007) ;(\mathrm{C})$ Aurora/2 $\times$ IG 12658 height, growth chamber $(\mathrm{n}=38$, $P(\mathrm{~W})=0.002)$; (D) Aurora/2 $\times$ IG 12658 average internode, growth chamber $(\mathrm{n}=38, P(\mathrm{~W})=0.059)$; (E) IG $114476 \times$ IG 12658 height, field $(\mathrm{n}=239, P(\mathrm{~W})=0.001) ;(\mathrm{F})$ IG $114476 \times$ IG 12658 average internode, field ( $\mathrm{n}=239, P(\mathrm{~W})=0.002) ;(\mathrm{G})$ IG $114476 \times$ IG 12658 height, growth chamber $(\mathrm{n}=61, P(\mathrm{~W})=0.032)$; (H) IG $114476 \times$ IG 12658 average internode, growth chamber $(n=61, P(\mathrm{~W})=0.001)$; $(\mathrm{I})$ Rinrei $\times$ IG 12658 height, field $(\mathrm{n}=314, P(\mathrm{~W})=0.001)$; (J) Rinrei $\times$ IG 12658 average internode, field $(\mathrm{n}=314, P(\mathrm{~W})$ $=0.001) ;(K)$ Rinrei $\times$ IG 12658 height, growth chamber $(\mathrm{n}=88, P(\mathrm{~W})=0.001) ;(\mathrm{L})$ Rinrei $\times$ IG 12658 average internode, growth chamber $(\mathrm{n}=88, P(\mathrm{~W})=0.451)$; $(\mathbf{M})$ IG $114476 \times$ Rinrei height, field $(\mathrm{n}=144$, $P(\mathrm{~W})=0.001)$; (N) IG $114476 \times$ Rinrei average internode, field $(\mathrm{n}=144, P(\mathrm{~W})=0.001) ;(\mathbf{O})$ Rinrei $\times$ IG 114476 height, field $(\mathrm{n}=44, P(\mathrm{~W})=0.308) ;(\mathbf{P})$ Rinrei $\times$ IG 114476 average internode, growth chamber $(\mathrm{n}=44, P(\mathrm{~W})=0.580) ;(\mathrm{Q})$ Rinrei $\times$ Aurora/2 height, field $(\mathrm{n}=93, P(\mathrm{~W})=0.349) ;(\mathbf{R})$ Rinrei $\times$ Aurora/2 average internode, field $(\mathrm{n}=93, P(\mathrm{~W})=0.139) . P(\mathrm{~W}), P$ value of the Shapiro-Wilk test for normality. 
The cross between the Rinrei and IG 12658 resulted in a normal height $\mathrm{F}_{1}$ plant, indicating the two height-related genes in this study were genetically and physiologically independent. Therefore, the dwarfing genes ( $d w f 1$ from IG 12658 and dwarf1 from Rinrei) were controlled by two independent recessive genes. The independent nature of these genes made it possible to create a genotype expressing both dwarfing genes (termed the double dwarf), resulting in a phenotype with extremely reduced height. The double dwarf phenotype occurred in a 15:1 ratio, fitting the double recessive genotypic model (Table 3).

Table 3. Chi-square results for the $F_{2}$ population of the cross Rinrei $\times$ IG 12658 testing independence of the two recessive dwarfing genes (9:7), and the double dwarf hypothesis (9:3:3:1 and 15:1).

\begin{tabular}{|c|c|c|c|c|c|c|}
\hline & $F_{2}$ & & & & & \\
\hline & Normal & Rinrei Semi-Dwf ${ }^{1}$ & IG 12658 Dwf & Double Dwf & & \\
\hline Field & 182 & 13 & & - & $\begin{array}{c}\chi^{2}(9: 7), \mathrm{df}=1 \\
0.374\end{array}$ & $\begin{array}{c}P \\
0.541\end{array}$ \\
\hline Growth chamber & 46 & 42 & & - & 0.566 & 0.452 \\
\hline Field & 182 & 50 & 62 & 20 & $\begin{array}{c}\chi^{2}(9: 3: 3: 1), \mathrm{df}=3 \\
1.674\end{array}$ & 0.643 \\
\hline Growth chamber & 46 & 22 & 13 & 7 & $v^{3.232}$ & 0.357 \\
\hline $\begin{array}{c}\text { Field } \\
\text { Growth chamber }\end{array}$ & $\begin{array}{c}294 \\
81\end{array}$ & - & - & $\begin{array}{c}20 \\
7\end{array}$ & $\begin{array}{c}\chi^{2}(15: 1), \mathrm{df}=1 \\
0.008 \\
0.436\end{array}$ & $\begin{array}{l}0.930 \\
0.509\end{array}$ \\
\hline
\end{tabular}

${ }^{1}$ Dwf, dwarf.

The means, standard deviations, and ranges of parental lines and $\mathrm{F}_{2}$ populations for branching are shown in Table 4. The average number of branches varied from $1.50 \pm 0.58$ (Aurora/2) to $6.14 \pm 1.00$ (IG 12658) under growth chamber conditions and from $4.60 \pm 1.52$ (IG 114476) to $6.14 \pm 1.07$ (IG 12658) under field conditions. A higher variation was found in the $F_{2}$ cross IG $114476 \times$ IG 12658 for a number of branches under the field conditions. Multiple $F_{2}$ populations were examined to determine the genetic control of branching. The phenotypic distribution patterns for the branch number for these populations did not show discrete categories, indicating a normal distribution of branch numbers. However, the Shapiro-Wilk test showed a non-normal distribution for the majority of these populations (Figure 2A-H).

Table 4. The mean \pm standard deviation (SD) and the range for the number of branches under the field and growth chamber conditions of parent lines and $\mathrm{F}_{2}$ faba bean crosses.

\begin{tabular}{cccc}
\hline Parental Line/ $\mathbf{F}_{2}$ Cross & & \multicolumn{2}{c}{ Number of Branches } \\
\hline & & Mean \pm SD & Range \\
\hline Aurora/2 & Field & $5.43 \pm 1.81$ & $3-6$ \\
& Growth chamber & $1.50 \pm 0.58$ & $1-2$ \\
IG 114476 & Field & $4.60 \pm 1.52$ & $3-8$ \\
& Growth chamber & $4.50 \pm 0.84$ & $3-6$ \\
IG 12658 & Field & $6.14 \pm 1.07$ & $5-8$ \\
& Growth chamber & $6.14 \pm 1.00$ & $5-8$ \\
Rinrei & Field & $6.00 \pm 1.0$ & $5-7$ \\
& Growth chamber & - & - \\
Aurora/2 $\times$ IG 114476 & Field & $8.50 \pm 4.20$ & $2-24$ \\
& Growth chamber & $3.00 \pm 0.79$ & $1-5$ \\
IG 114476 $\times$ Aurora/2 & Field & $6.04 \pm 3.24$ & $1-21$ \\
IG 114476 $\times$ IG 12658 & Growth chamber & $3.14 \pm 0.87$ & $1-5$ \\
& Field & $9.07 \pm 3.68$ & $2-26$ \\
Rinrei $\times$ IG 114476 & Growth chamber & $4.59 \pm 1.58$ & $2-10$ \\
IG 114476 $\times$ Rinrei & Field & $8.52 \pm 3.00$ & $4-16$ \\
S.E.M. ${ }^{1}$ & Field & $6.86 \pm 3.30$ & $1-22$ \\
& & 0.38 & \\
\hline
\end{tabular}

${ }^{1}$ S.E.M., Standard errors of means. 


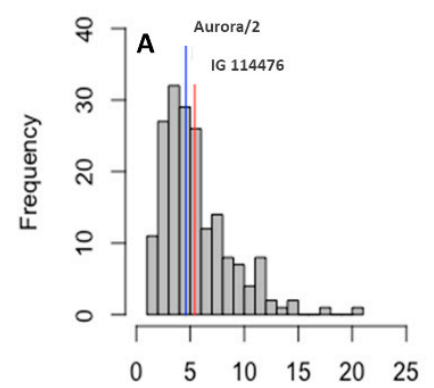

Branch number

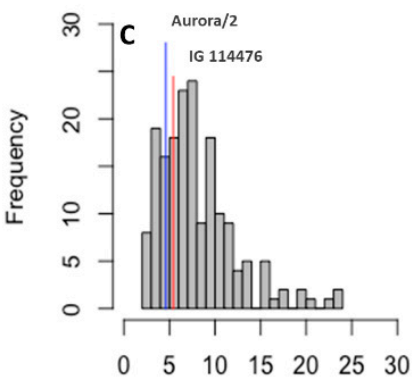

Branch number
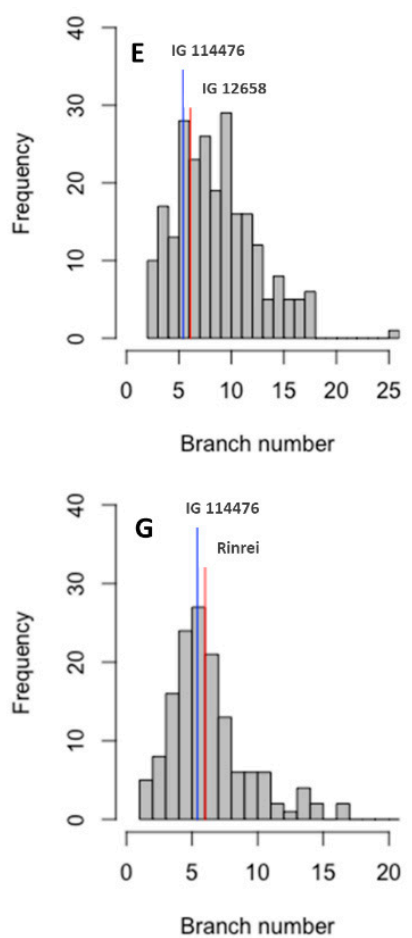
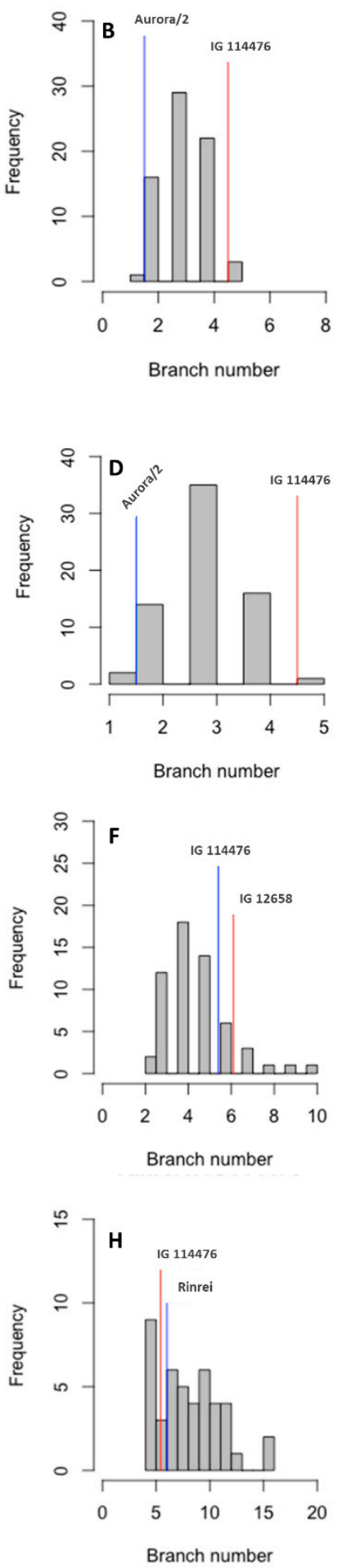

Figure 2. Frequency distributions of the number of branches for $F_{2}$ populations. (A) IG $114476 \times$ Aurora/2, field ( $\mathrm{n}=185, P(\mathrm{~W})=0.001)$; (B) IG $114476 \times$ Aurora/2, growth chamber $(\mathrm{n}=71, P(\mathrm{~W})=0.115)$; (C) Aurora/2 $\times$ IG 114476, field $(\mathrm{n}=177, P(\mathrm{~W})=0.001)$; (D) Aurora/2 $\times$ IG 114476, growth chamber ( $\mathrm{n}=68, P(\mathrm{~W})=0.001)$; (E) IG $114476 \times$ IG 12658, field $(\mathrm{n}=239, P(\mathrm{~W})=0.001) ;(\mathrm{F})$ IG $114476 \times \mathrm{IG}$ 121658 , growth chamber $(\mathrm{n}=61, P(\mathrm{~W})=0.132) ;(\mathrm{G})$ IG $114476 \times$ Rinrei, field $(\mathrm{n}=144, P(\mathrm{~W})=0.001)$; (H) IG $114476 \times$ Rinrei, growth chamber $(\mathrm{n}=44, P(\mathrm{~W})=0.001) . P(\mathrm{~W}), P$ value of Shapiro-Wilk test for normality. 


\section{Discussion}

Dwarfism and branching are both architectural phenotypes that impact plant competitiveness and visual appearance. We show that these two traits in faba bean were inherited differently. Both dwarfing and semi-dwarfing genes investigated in this study fit a single recessive gene model and were, therefore, qualitatively inherited and independent. In contrast, segregation for branch number was not discrete. Branching had continuous segregation, indicative of quantitative inheritance and, therefore, more difficult to manipulate from a breeding perspective.

Faba bean plant height is known to vary from dwarf to towering giants. The semi-determinate nature of faba bean [25] and its large genetic variation can result in enormous plants if grown in long and favorable growing seasons, such as in New Zealand, where plants with a height of $250 \mathrm{~cm}$ have been reported [26]. A study on a large faba bean germplasm collection, consisting of over 5000 accessions had an average height of $78 \mathrm{~cm}$, with a range of 10.3 to $201.5 \mathrm{~cm}$ [21]. Our results also revealed relatively large variations in plant height and internode length in the $F_{2}$ segregation population, particularly when the lines with contrasting height profiles were crossed (e.g., Aurora/2 $\times$ IG 12658).

Dwarfism is a well-known and widely adopted phenomenon in plant improvement [27]. The ability to manipulate plant height can lead to increased yield, vigor, and agronomic characteristics [28,29]. Aside from field crop agriculture, dwarfism is also used in more intensive production systems in horticulture. Smaller plants are easier to grow, harvest, and maintain; therefore, dwarf varieties of many horticultural plants exist, from fruit trees to landscaping grasses [30]. Here we show that the dwff gene from IG 12658 reduced internode length nearly 1.5-fold compared to Aurora/2 (tall). In the studied populations, phenotypic expression of dwarfism was consistent, regardless of the normal parent genotype, when crossed with the dwarf parental line. This indicates dwarfism was not influenced by either the physical or the genetic environment, and consistently segregated 3:1. Indeterminate growth habits also affect plant height and, together with the internode length, might lead to a prolonged growth cycle with consequences for maturation, and also strong within-plant competition for nutritive assimilates between reproductive and vegetative growth processes. The genetics of determinate growth habit in faba bean has been identified [31], and molecular markers were developed to assist in selection for this trait $[32,33]$. However, the literature on dwarfism in faba bean is generally lacking on gene location (s) or the molecular basis for variation of plant height.

The dwarf gene has been shown to have pleiotropic phenotypic effects causing dark green foliage in faba bean [6,7]. Pleiotropy in this study was confirmed with the dwarf1 from Rinrei. It conveyed multiple phenotypic effects on plants, including dark green foliage, short stature, short petioles, and thick stems. In contrast to the results of Fukuta et al. [7], our results under both climate controlled and field conditions identified the Rinrei dwarfing gene to be expressed as a slow growth gene, rather than a dwarf/semi-dwarf. The slower growth reduced the initial growth rate during the pre-flowering period, causing the appearance of early season dwarfism, but plants continued to grow and eventually no longer appeared to be dwarfed. The Rinrei phenotype is known to be caused by a brassinosteroid deficiency, which explains the reduction in cell expansion and elongation [7]. However, Rinrei should be classified as a slow-growth phenotype rather than dwarf. The dwf 1 gene from IG 12658 had no obvious pleiotropic effects with the dark green foliage.

Inheritance of the branched phenotype in this experiment was more challenging to characterize. The degree of branching in faba bean is influenced by the environment [34]. To account for that, the same populations were grown in two environments to observe the highly branched trait. As shown in Table 4, in $F_{2}$ populations, the branch number was consistently higher when plants were grown in field conditions in comparison to the branch numbers under the growth chamber conditions. Interestingly, IG 117746 had the most consistent number of branches regardless of environment, indicating a strong genotype effect. An additional possibility that could be influencing these observations is the development of secondary branching. Secondary branching was characterized by the production of new branches late in the growing season. Secondary branching is common in faba bean, and is 
more prominent in winter-sown types [25]. Rinrei is a winter-sown type faba bean and had more secondary branches than IG 117746. IG 12658 had more branches than IG 117746 (Table 4), indicating that this dwarf type could also be considered a highly branched type. Understanding the inheritance of branching could be useful for the development of more competitive varieties for use in organic farming systems, for example, in the development of intercropping systems for weed suppression.

Plant architecture is an important component of faba bean breeding. The modification of plant architecture is known to have a significant impact on crop adaptation and yield [35,36]. The large diversity over many architectural traits of faba bean (e.g., height and branching) would facilitate breeding for multiple uses, as well as optimizing plant yield. An example of this breeding strategy exists, for example, in soybean (Glycine max (L.) Merr. where breeders target tall plants with many branches [37].

\section{Conclusions}

We have shown that dwarfism and branching in faba bean were controlled qualitatively and quantitatively, respectively. Sources of dwarfism and semi-dwarfism in this study were controlled by independent single recessive genes. Our results also confirmed that Rinrei-type plants are semi-dwarfs. These genes had an additive effect on plant height. Branching was controlled by multiple genes and, therefore, could not be genetically characterized within the scope of this study. The dwarfism was unaffected by environmental conditions, but branching was affected by the environment. Modulating faba bean architecture could be a key to improve the adaptation of the crops to different environments that may lead to increasing seed yield and stability.

Author Contributions: Conceptualization, A.V. and H.K.; writing-original draft preparation, J.H. and H.K.; writing-review and editing, A.V. and H.K. All authors have read and agreed to the published version of the manuscript.

Funding: The authors acknowledge funding from Agriculture Development Fund (Government of Saskatchewan, Canada); Western Grains Research Foundation, Canada; Saskatchewan Pulse Growers, Canada; and the NORFAB (Protein for the Northern Hemisphere) project funded by Innovation Fund Denmark. J.H. expresses her gratitude for the financial support of Robert P. Knowles Scholarship at the University of Saskatchewan, Canada.

Acknowledgments: The authors thank Donal O'Sullivan (University of Reading, UK) for providing the seeds of accession IG 12658 (NV153).

Conflicts of Interest: The authors declare no conflict of interest.

\section{References}

1. Hedden, P. The gene of the Green Revolution. Trends Genet. 2003, 19, 5-9. [CrossRef]

2. Huyghe, C. Genetics and genetic modifications of plant architecture in grain legumes: A review. Agronomie 1998, 18, 383-411. [CrossRef]

3. Bond, D.A.; Fyfe, J.L. Breeding field beans. Plant Breed. 1962, 4-26.

4. Sjödin, J. Induced morphological variation in Vicia faba L. Hereditas 1971, 67, 155-180. [CrossRef]

5. Ward, S.; Chapman, G.P. (Eds.) ICARDA (International Center for Agricultural Research in the Dry Areas). In Third Conspectus of Genetic Variation within Vicia faba; Faba Bean Information Service: Aleppo, Syria, 1986; p. 54 .

6. Filippetti, A. Inheritance of dwarf growth habit, induced in Vicia faba L. var major by ethyl methane sulfonate (EMS). FABIS Newsl. 1988, 20, 15-18.

7. Fukuta, N.; Fujiok, S.; Takatsuto, S.; Yoshida, S.; Fukuta, Y.; Nakayama, M. 'Rinrei', a brassinosteroid-deficient dwarf mutant of faba bean (Vicia faba L.). Physiol. Plant. 2004, 121, 506-512. [CrossRef]

8. Fukuta, N.; Fukuzono, K.; Kawaide, H.; Abe, H.; Nakayama, M. Physical restriction of pods causes seed size reduction of a brassinosteroid-deficient faba bean (Vicia faba). Ann. Bot. 2006, 97, 65-69. [CrossRef]

9. van Norel, A.; Hoogendoorn, J. Faba bean dwarf selections outyield Dutch top varieties. FABIS Newsl. 1989, $25,10-13$. 
10. Webb, A.; Cottage, A.; Wood, T.; Khamassi, K.; Hobbs, D.; Gostkiewicz, K.; White, M.; Khazaei, H.; Ali, M.; Street, D.; et al. A SNP-based consensus genetic map for synteny-based trait targeting in faba bean (Vicia faba L.). Plant. Biotech. J. 2016, 14, 177-185. [CrossRef]

11. Ogas, J. Plant hormones: Dissecting the gibberellin response pathway. Curr. Biol. 1998, 8, 165-167. [CrossRef]

12. Peng, J.R.; Richards, D.E.; Hartley, N.M.; Murphy, G.P.; Devos, K.M.; Flintham, J.E.; Beales, J.; Fish, L.J.; Worland, A.J.; Pelica, F.; et al. 'Green revolution' genes encode mutant gibberellin response modulators. Nature 1999, 400, 256-261. [CrossRef]

13. Bajguz, A.; Tretyn, A. The chemical characteristic and distribution of brassinosteroids in plants. Phytochemistry 2003, 62, 1027-1046. [CrossRef]

14. Nomura, T.; Nakayama, M.; Reid, J.B.; Takeuchi, Y.; Yokota, T. Blockage of brassinosteroid biosynthesis and sensitivity cause dwarfism in garden pea. Plant. Physiol. 1997, 113, 31-37. [CrossRef]

15. Kwon, M.; Choe, S. Brassinosteroid biosynthesis and dwarf mutants. J. Plant. Biol. 2005, 48, 1. [CrossRef]

16. Castorina, G.; Consonni, G. The role of brassinosteroids in controlling plant height in Poaceae: A genetic perspective. Int. J. Mol. Sci. 2020, 21, 1191. [CrossRef]

17. Pilbeam, C.J.; Hebblethwaite, P.D.; Clark, A.S. Effect of different inter-row spacings on faba beans of different form. Field Crops Res. 1989, 21, 203-214. [CrossRef]

18. Spies, J.M.; Warkentin, T.D.; Shirtliffe, S.J. Variation in field pea (Pisum sativum) cultivars for basal branching and weed competition. Weed Sci. 2011, 59, 218-223. [CrossRef]

19. Franklin, K.A. Shade avoidance. New Phytol. 2008, 179, 930-944. [CrossRef]

20. Duc, G. Faba bean (Vicia faba L.). Field Crops Res. 1997, 53, 99-109. [CrossRef]

21. Zong, X.; Cheng, X.; Wang, S. Food legume crops. In Crops and Its Relative Species in China Grain Crops; Yuchen, D., Diansheng, Z., Eds.; China Agriculture: Beijing, China, 2006; pp. 406-479.

22. Khazaei, H.; Stoddard, F.L.; Purves, R.W.; Vandenberg, A. A multi-parent faba bean (Vicia faba L.) population for future genomic studies. Plant Genet. Resour. 2018, 16, 419-423. [CrossRef]

23. Khazaei, H.; Wach, D.; Pecio, A.; Vandenberg, A.; Stoddard, F.L. Genetic analysis of photosynthesis-related traits in faba bean (Vicia faba L.) for crop improvement. Plant. Breed. 2019, 138, 761-769. [CrossRef]

24. R Core TeamR. A Language and Environment for Statistical Computing; R Foundation for Statistical Computing: Vienna, Austria, 2019; Available online: http://www.R-project.org/ (accessed on 20 June 2020).

25. Knott, C.M. A key for stages of development of the faba bean (Vicia faba). Ann. Appl. Biol. 1990, 116, 391-404. [CrossRef]

26. Foundation for Arable Research. Faba Beans-A Growers' Guide. FAR Focus, 2012. Available online: https://www.far.org.nz/assets/files/uploads/26313_FAR_focus_8_-_faba_beans.pdf (accessed on 28 June 2020).

27. Milach, S.C.K.; Federizzi, L.C. Dwarfing genes in plant improvement. Adv. Agron. 2001, 73, $35-63$.

28. Heath, M.C.; Pilbeam, C.J.; McKenzie, B.A.; Hebblethwaite, P.D. Plant architecture, competitive ability and crop productivity in food legumes with particular emphasis on pea (Pisum sativum L.) and faba bean (Vicia faba L.). In Expanding the Production and Use of Cool Season Food Legumes. Current Plant Science and Biotechnology in Agriculture; Muehlbauer, F.J., Kaiser, W.J., Eds.; Springer: Dordrecht, The Netherlands, 1994; Volume 19, pp. 771-790.

29. Mathan, J.; Bhattacharya, J.; Ranjan, A. Enhancing crop yield by optimizing plant developmental features. Development 2016, 143, 3283-3294. [CrossRef]

30. Clark, D.; Klee, H.; Dandekar, A. Despite benefits, commercialization of transgenic horticultural crops lags. Calif. Agric. 2004, 58, 89-98. [CrossRef]

31. Filippetti, A. Inheritance of determinate growth habit induced in Vicia faba major by ethyl methane sulphonate (EMS). FABIS Newsl. 1986, 15, 12-14.

32. Avila, C.; Atienza, S.; Moreno, M.; Torres, A. Development of a new diagnostic marker for growth habit selection in faba bean (Vicia faba L.) breeding. Theor. Appl. Genet. 2007, 115, 1075-1082. [CrossRef]

33. Cottage, A.; Gostkiewicz, K.; Thomas, J.; Borrows, R.; Torres, A.M.; O'Sullivan, D.M. Heterozygosity and diversity analysis using mapped single nucleotide polymorphisms in a faba bean inbreeding programme. Mol. Breed. 2012, 30, 1799-1809. [CrossRef]

34. Abu-Amer, J.H.; Saoub, H.M.; Akash, M.W.; Al-Abdallat, A.M. Genetic and phenotypic variation among faba bean landraces and cultivars. Int. J. Veg. Sci. 2010, 17, 45-59. [CrossRef]

35. Busov, V.B.; Brunner, A.M.; Strauss, S.H. Genes for control of plant stature and form. New Phytol. 2008, 177, 589-607. [CrossRef] 
36. Wang, Y.; Li, J. Molecular basis of plant architecture. Ann. Rev. Plant. Biol. 2008, 59, 253-279. [CrossRef]

37. Sun, Z.; Su, C.; Yun, J.; Jiang, Q.; Wang, L.; Wang, Y.; Cao, D.; Zhao, F.; Zhao, Q.; Zhang, M.; et al. Genetic improvement of the shoot architecture and yield in soya bean plants via the manipulation of GmmiR156b. Plant. Biotech. J. 2019, 17, 50-62. [CrossRef]

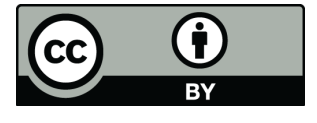

(C) 2020 by the authors. Licensee MDPI, Basel, Switzerland. This article is an open access article distributed under the terms and conditions of the Creative Commons Attribution (CC BY) license (http://creativecommons.org/licenses/by/4.0/). 